\begin{tabular}{|c|c|}
\hline Title & Fabrication of A nodic Nanoporous A lumina via A cety lenedicarboxylic A cid A nodizing \\
\hline Author(s) & Kikuchi, Tatsuya; Nishinaga, O samu; Natsui, Shungo; Suzuki, Ryosuke. 0. \\
\hline Citation & $\begin{array}{l}\text { ECS Electrochemistry Letters, 3(7), C25-C28 } \\
\text { https://doi.org/10.1149/2.0071407eel }\end{array}$ \\
\hline Issue Date & 2014 \\
\hline Doc URL & http:/hdl.handle.net/2115/56407 \\
\hline Rights & $\begin{array}{l}\text { (1) The Electrochemical Society, Inc. 2014. All rights reserved. Except as provided under U.S. copyright law, this work } \\
\text { may not be reproduced, resold, distributed, or modified without the express permi ssion of The Electrochemical Society } \\
\text { (ECS). The archival version of this work was published in ECS Electrochemistry Letters. }\end{array}$ \\
\hline Type & article (author version) \\
\hline File Information & ADCA 2.pdf \\
\hline
\end{tabular}

Instructions for use 


\section{Fabrication of Anodic Nanoporous Alumina via Acetylenedicarboxylic Acid Anodizing}

Tatsuya Kikuchi", Osamu Nishinaga, Shungo Natsui, and Ryosuke O. Suzuki Faculty of Engineering, Hokkaido University

N13-W8, Kita-ku, Sapporo, Hokkaido, 060-8628, Japan

*Corresponding author: Tatsuya Kikuchi

TEL: +81-11-706-6340

FAX: +81-11-706-6342

E-mail: kiku@eng.hokudai.ac.jp 


\begin{abstract}
The nano-morphologies of anodic porous alumina formed via anodizing in a new electrolyte, acetylenedicarboxylic acid (ADCA), are described. Anodic oxides grew uniformly on the aluminum at voltage of 87.5-95.0 V, but a burned black oxide film was formed at higher voltage. The burning voltage and the current density under steady-state oxide growth decreased with solution temperature. An anodic porous alumina film with a cell size of $250 \mathrm{~nm}$ and nanopores measuring $100 \mathrm{~nm}$ could be successfully obtained by ADCA anodizing. The anodic porous alumina possessed numerous non-straight nanopores due to the branching and extinction of the nanopores during anodizing.
\end{abstract}

Key words: Aluminum; Anodizing; Anodic Porous Alumina; Acetylenedicarboxylic Acid; Nanoporous Structure 


\section{Introduction}

Anodic porous alumina with numerous nanometer-scale pores can be easily formed on aluminum by electrochemical anodizing ${ }^{1-3}$ and has been widely investigated by many researchers in the field of nanostructure applications ${ }^{4-9}$. The nano-morphology of anodic porous alumina is limited by the narrow range of electrolyte species used for anodizing ${ }^{10-13}$. Each electrolyte operates effectively at an appropriate anodizing voltage, which has a great effect on the cell size (identical meaning to interpore distance) and pore diameter of the resulting anodic porous alumina film ${ }^{14,15}$. Only a few inorganic and organic electrolytes, such as sulfuric $\left(\mathrm{H}_{2} \mathrm{SO}_{4}\right)^{16}$, phosphoric $\left(\mathrm{H}_{3} \mathrm{PO}_{4}\right)^{17}$, chromic $\left(\mathrm{H}_{2} \mathrm{CrO}_{4}\right)^{18}$, and several carboxylic acids, including oxalic acid $\left((\mathrm{COOH})_{2}\right)^{19-23}$, have been reported for porous alumina fabrication to date, and there has been no report on the development of a new anodizing electrolyte in recent decades. However, the discovery of additional electrolytes would greatly expand the applicability of anodic porous alumina. Very recently, we reported on new electrolytes for anodic porous alumina, selenic $\left(\mathrm{H}_{2} \mathrm{SeO}_{4}\right)$ and squaric (3,4-dihydroxy-3-cyclobutene-1,2-dione) acids ${ }^{13,24}$. In these studies, we observed that anodic porous alumina characteristics different from those yielded by typical electrolytes can be obtained by anodizing using selenic and squaric acids.

In the present investigation, we studied a new electrolyte for anodic porous alumina fabrication, acetylenedicarboxylic acid $\left(\mathrm{C}_{4} \mathrm{H}_{2} \mathrm{O}_{4}, \mathrm{HOOC}-\mathrm{C} \equiv \mathrm{C}-\mathrm{COOH}, \mathrm{ADCA}\right)$. Anodic porous alumina can typically be formed by anodizing in acidic electrolyte with low dissociation constants, $\mathrm{pKa}_{1}$ and $\mathrm{pKa}_{2}{ }^{13,14}$. ADCA is a dicarboxylic acid, with a triple bond at the center, with relatively low $\mathrm{pKa}$ values of 0.66 and $2.34^{25}$;

$$
\begin{aligned}
\mathrm{HOOC}-\mathrm{C} \equiv \mathrm{C}-\mathrm{COOH} & \rightleftarrows \mathrm{H}^{+}+\mathrm{HOOC}-\mathrm{C} \equiv \mathrm{C}-\mathrm{COO}^{-} \quad\left(\mathrm{pKa}_{1}=0.66\right) \\
\mathrm{HOOC}-\mathrm{C} \equiv \mathrm{C}-\mathrm{COO}^{-} & \rightleftarrows \mathrm{H}^{+}+\mathrm{OOC}-\mathrm{C} \equiv \mathrm{C}-\mathrm{COO}^{2-} \quad\left(\mathrm{pKa}_{2}=2.34\right)
\end{aligned}
$$

It is strongly believed that ADCA has the potential to behave as a suitable electrolyte for anodic porous alumina fabrication because of its sufficiently low dissociation constants. We describe for the first time the growth behavior of an anodic oxide formed by anodizing in ADCA and examined the corresponding nanostructures by electron scanning microscopy (SEM).

\section{Experimental}

High-purity aluminum foils (99.99 wt\%, $110 \mu \mathrm{m}$ thick, Showa Aluminum Co., Japan) were cut into $20 \times 20 \mathrm{~mm}^{2}$ pieces and used as the anodizing specimens. The specimens were ultrasonically degreased in an ethanol solution for $10 \mathrm{~min}$ and then chemically polished in a $1.0 \mathrm{M} \mathrm{NaOH}$ solution $(333 \mathrm{~K})$ for $30 \mathrm{~s}$. After chemical polishing, the specimens were immersed in a 0.3 M ADCA solution ( $\mathrm{T}=273-333 \mathrm{~K}, \mathrm{pH}=0.88$ at 294 $\mathrm{K}$, Tokyo Chemical Industry Co.) and then anodized for $180 \mathrm{~min}$ at a constant voltage in the range of 87.5 to $97.5 \mathrm{~V}$. An extremely simple two-electrode electrochemical cell with a platinum counter electrode and a water bath was used in the anodizing process. The solutions were vigorously stirred with a magnetic stirrer during anodizing. To 
examine the growth behavior at the interface between the anodic oxide and aluminum substrate, the anodized specimens were immersed in a $0.20 \mathrm{M} \mathrm{CrO}_{3} / 0.51 \mathrm{M} \mathrm{H}_{3} \mathrm{PO}_{4}$ solution $(353 \mathrm{~K})$ to selectively dissolve the anodic oxide formed on the aluminum substrate, and the interface was thus exposed. After each process, the specimens were washed with distilled water and then dried in a desiccator.

The surface, interface, and cross-sectional morphologies of the anodized specimens were examined by field emission scanning electron microscopy (FE-SEM, JSM-6500F and JIB-4600F/HKD, JEOL, Japan). A platinum electro-conductive layer was sputter-coated on the specimens using a sputter coater (MSP-1S, Vacuum Device Co., Japan). For the observations of the cross-section, the specimens were mechanically cut.

\section{Results and discussion}

Figure 1 shows the changes in the current density with anodizing time at several constant anodizing voltages in a 0.3 M ADCA solution at a) $\mathrm{T}=333$, b) 313, c) 293, and d) $273 \mathrm{~K}$. At $\mathrm{T}=293 \mathrm{~K}$, the current density increased rapidly to over $20 \mathrm{~A} \mathrm{~m}^{-2}$ in the initial period of $20 \mathrm{~min}$ at $92.5 \mathrm{~V}$, and oxygen gas production was observed from the surface after this increase. A non-uniform black oxide was observed on the top of the specimen, although an anodic oxide with a light-yellow color was formed on other surface (Fig. 1e, right). This black oxide was induced by "burning phenomena" due to a high current density resulting from the high electric field applied ${ }^{26}$. At 90.0 and $87.5 \mathrm{~V}$, the current-time transients show changes that are typical for anodic porous alumina under constant voltage anodizing; the increase and decrease in current density over 30 min correspond to the formation of pores in the barrier oxide, and the subsequent plateau current corresponds to the steady growth of the porous layer. The current density slightly decreased with anodizing voltage due to a decrease in the growth rate of the anodic oxide. An anodic oxide with a light-yellow color was uniformly formed on the specimen under these anodizing conditions (Fig. 1e, left).

Comparing Fig. 1a) through 1d), the peak current densities, corresponding to porous layer formation, were shifted to longer times with decreasing solution temperature (5 $\min$ at $333 \mathrm{~K}$ to $120 \mathrm{~min} 273 \mathrm{~K}$ ). This remarkable delay is attributed to the slow initiation of nanopore formation due to low chemical reactivity at low solution temperature. In addition, the plateau current density under steady-state growth also decreased with solution temperature. It is expected that the growth rate of the anodic oxide under steady-state growth decreases with solution temperature. The current-time transients shown in Fig. 1 suggest that a porous alumina film was formed on the aluminum surface by ADCA anodizing.

Figure 2a) shows an SEM image of the aluminum surface after chemical polishing in $\mathrm{NaOH}$ solution for $30 \mathrm{~s}$. A linear striped pattern, from top to bottom, formed by hot rolling; in addition, numerous etched concave structures measuring approximately a few hundred nanometers can be observed on the aluminum specimen. When this specimen was anodized in $0.3 \mathrm{M}$ ADCA solution at $293 \mathrm{~K}$ and $90.0 \mathrm{~V}$ for $180 \mathrm{~min}$, an anodic 
oxide with numerous concave structures, which corresponds to the network shape of the chemically etched concave structures, was formed on the aluminum surface (Fig. 2b). High-magnification SEM imaging (Fig. 2c) revealed that a large number of nanopores measuring approximately $25-35 \mathrm{~nm}$ in diameter were formed in the anodic oxide, a morphology that is typically observed on anodic porous alumina films. Moreover, an anodic oxide film measuring approximately $3 \mu \mathrm{m}$ in thickness was uniformly formed on the aluminum substrate, and numerous nanopores were observed in the anodic oxide, from the observation of the vertical cross-sectional image (Fig. 2d). Clearly, ADCA is identified as a new anodizing electrolyte for anodic porous alumina fabrication, based on the aforementioned electrochemical measurements and SEM observations. Figure 2e) shows an SEM image of the exposed aluminum substrate, which corresponds to the interface between the anodic oxide and the substrate, after anodizing and selective dissolution of the anodic porous alumina. A disordered array of dimples measuring 247 $\mathrm{nm}$ in average diameter was distributed on the aluminum substrate. The linear relation between the anodizing voltage and the cell size under the appropriate self-ordering condition has been reported by several research groups 5,11 , and it is described as follows:

$$
\mathrm{D}=2.5 \mathrm{~V}[\mathrm{~nm}]
$$

where $\mathrm{D}$ is the diameter of the cell in the anodic porous alumina and the value of 2.5 is the proportionality constant $\left(\mathrm{K}_{1}\right)$. The proportionality constant of our result $\left(\mathrm{K}_{1}=2.74\right.$ $\mathrm{nmV}^{-1}$ ) is slightly larger than that attained under the self-ordering condition because of the disordered growth of the porous alumina film. The nanodimple arrays were also disordered under all conditions described in Fig. 1.

Figure 3 shows SEM images of the vertical cross-section of the specimen anodized at $333 \mathrm{~K}$ and $95.0 \mathrm{~V}$ for $180 \mathrm{~min}$. It is clearly observed that a thick anodic porous alumina film with a thickness greater than $10 \mu \mathrm{m}$ was formed on the aluminum substrate. Numerous nanopores grew in the anodic oxide from the top surface to the bottom interface, although it appeared that the growth direction of the pores was not uniformly straight. This non-uniform growth of nanopores was observed under all anodizing conditions described in this investigation. High-magnification SEM imaging (Fig. 3b) shows that nanopores measuring approximately $110 \mathrm{~nm}$ in diameter were generated from the surface in a disorderly fashion, because nano-imprinting or two-step anodizing process was not applied to the aluminum specimen. In addition to the surface, several pore-branching and dead-pores were observed in the anodic oxide due to the disordered growth (Fig. 3c). Under these disordered growth conditions, it is considered that self-ordered anodic porous alumina could not be formed on the aluminum. A barrier oxide film with a thickness of $116 \mathrm{~nm}$ was clearly observed at the bottom of the anodic porous alumina (Fig. 3d). The proportionality constant $\left(\mathrm{K}_{2}\right)$ for the barrier oxide at the bottom of the porous alumina can be calculated using the following equation:

$$
\mathrm{K}_{2}=\delta / \mathrm{E}_{\mathrm{a}}
$$

where $\delta$ is the thickness of the barrier oxide and $E_{a}$ is the anodizing potential (i.e., 
voltage). By substituting $116 \mathrm{~nm}$ for $\delta$ and $95.0 \mathrm{~V}$ for $\mathrm{E}_{\mathrm{a}}, \mathrm{K}_{2}$ is estimated to be 1.22 $\mathrm{nmV}^{-1}$. This value, obtained from the cross-sectional image, agrees well with the values measured from anodizing in other electrolytes ${ }^{24,27}$.

Typical anodizing voltages in various carboxylic electrolytes for anodic porous alumina fabrication, including those used in our study, are summarized in Table. 1. Oxalic, malonic, and tartaric acids have been reported as self-ordering electrolytes for anodic porous alumina, and typical ordering voltages are determined to be 40,120, and $195 \mathrm{~V}$, respectively. Malic, citric, and glycolic acids operate over anodizing voltage ranges of approximately 200-250, 260-450, and $150 \mathrm{~V}$, although obtaining a highly self-ordered porous alumina film under these conditions is difficult because of the high electric field, high dissociation constants (malic and citric acids), and the use of monoprotic acid (glycolic acid). In fact, highly ordered porous alumina could only be obtained by anodizing in diacids or triacids with low dissociation constants, such as sulfuric, oxalic, phosphoric, and selenic acids. It is noted that our ADCA anodizing technique is effective at an unutilized voltage range of $87.5-95.0 \mathrm{~V}$ in previously described organic electrolytes. It is a well-known experimental fact that the nano-morphology, including pore diameter and cell size, strongly depends on the anodizing voltage ${ }^{10,11,13,28-30}$. Therefore, ADCA anodizing is extremely useful for controlling and changing the nano-morphology of porous alumina for nanostructure fabrication. We consider that a novel anodic porous alumina with an unutilized morphologies can be fabricated by ADCA anodizing. Further studies of ADCA anodizing under other electrochemical conditions, including electrolyte various concentrations, may lead to the self-ordering of anodic porous alumina films. Moreover, an appropriate ADCA anodizing procedure combined with the nano-imprinting technique and two-step anodizing may allow for the fabrication of highly ordered anodic porous alumina with a cell size of $250 \mathrm{~nm}$.

\section{Conclusions}

We described the first anodic porous alumina film formed by acetylenedicarboxylic acid anodizing at various constant voltages and solution temperatures and the nano-morphology of the resulting film. Unlike the organic electrolytes that have typically been used for fabricating anodic porous alumina to date, acetylenedicarboxylic acid possesses a triple bond and an extremely low $\mathrm{pH}$ value. An anodic porous alumina film can be successfully formed via anodizing in $0.3 \mathrm{M}$ acetylenedicarboxylic acid solution at 87.5-95.0 V. Further-high voltage anodizing causes the non-uniform formation of black oxide by burning. Conversely, low voltage anodizing causes the slow growth rate of the anodic porous alumina. These anodizing conditions are not suitable for anodic porous alumina fabrication. The anodic porous alumina film fabricated in this study possessed a cell size of $250 \mathrm{~nm}$ and pore diameter of $100 \mathrm{~nm}$. Our porous alumina film is expected to serve as a nanotemplate for various nano-applications in manufacturing at the $250-\mathrm{nm}$ scale. 
Acknowledgments

This research was conducted at Hokkaido University and was supported by the "Nanotechnology Platform" Program of the Ministry of Education, Culture, Sports, Science and Technology (MEXT), Japan. This work was financially supported by the Japan Society for the Promotion of Science (JSPS) "KAKENHI" and by the Japan Aluminum Association. 


\section{References}

1) G. E. Thompson, Thin Solid Films, 297, 192 (1997).

2) J. E. Houser and K. R. Hebert, Nat. Mater., 8, 415 (2009).

3) K. R. Hebert, S. P. Albu, I. Paramasivam, and P. Schmuki, Nat. Mater., 11, 162 (2012).

4) H. Masuda and K. Fukuda, Science, 268, 1466 (1995).

5) W. Lee, R. Ji, U. Gösele, and K. Nielsch, Nat. Mater., 5, 741 (2006).

6) W. Lee, K. Schwirn, M. Steinhart, E. Pippel, R. Scholz, and U. Gösele, Nat. Nanotechnol., 3, 234 (2008).

7) H. Masuda, H. Yamada, M. Satoh, H. Asoh, M. Nakao, and T. Tamamura, Appl. Phys. Lett., 71, 2770 (1997).

8) E. Kurowska, A. Brzózka, M. Jarosz, G. D. Sulka, and M. Jaskuła, Electrochim. Acta, 104, 439 (2013).

9) S. Samanman, C. Thammakhet, P. Kanatharana, C. Buranachai, and P. Thavarungkul, Electrochim. Acta, 102, 342 (2013).

10) S. Ono, M. Saito, M. Ishiguro, and H. Asoh, J. Electrochem. Soc., 153, B473 (2004).

11) S. Z. Chu, K. Wada, S. Inoue, M. Isogai, Y. Katsuta, and A. Yasumori, J. Electrochem. Soc., 153, B384 (2006).

12) M. Michalska-Domańska, M. Norek, W. J. Stępniowski, and B. Budner, Electrochim. Acta, 105, 424 (2013).

13) T. Kikuchi, T. Yamamoto, S. Natsui, and R. O. Suzuki, Electrochim. Acta, 123, 14 (2014).

14) S. Ono, M. Saito, and H. Asoh, J. Electrochem. Soc., 51, 827 (2005).

15) A. P. Li, F. Müller, A. Birner, K. Nielsch, and U. Gösele, J. Vac. Sci. Technol. A, 17, 1428 (1999).

16) H. Masuda, F. Hasegwa, and S. Ono, J. Electrochem. Soc., 144, L127 (1997).

17) H. Masuda, K. Yada, and A. Osaka, Jpn. J. Appl. Phys., 37, L1340 (1998).

18) W. J. Stępniowski, M. Michalska-Domańska, M. Norek, and T. Czujko, Mater. Lett., 117, 69 (2014).

19) H. Jha, T. Kikuchi, M. Sakairi, and H. Takahashi, Nanotechnology, 19, 395603 (2008).

20) L. A. Meier, A. E. Alvarez, D. R. Salinas, and M. C. del Barrio, Mater. Lett., 70, 119 (2012).

21) S. J. Garcia-Vergara, P. Skeldon, and G. E. Thompson, Appl. Surf. Sci., 254, 1534 (2007).

22) A. Mozalev, I. Mozaleva, M. Sakairi, and H. Takahashi, Electrochim. Acta, 50, 5065 (2005).

23) T. Kikuchi, T. Yamamoto, and R. O. Suzuki, Appl. Surf. Sci., 284, 907 (2013).

24) O. Nishinaga, T. Kikuchi, S. Natsui, and R. O. Suzuki, Sci. Rep., 3, 2748 (2013).

25) L. M. Schwartz, R. I. Gelb, and D. A. Laufer, J. Chem. Eng. Data. 25, 95 (1980). 
26) T. Aerts, I. De Graeve, and H. Terryn, Electrochim. Acta, 54, 270 (2008).

27) M. S. Hunter and P. Fowle, J. Electrochem. Soc., 101, 481 (1954).

28) F. Li, L. Zhang, and R. M. Metzger, Chem. Mater., 10, 2470 (1998)

29) S. Banerjee, Y. Myung, and P. Banerjee, RSC Adv., 4, 7919 (2004)

30) M. Pashchanka and J. Schneider, J. Mater. Chem., 21, 18761 (2011) 


\section{Captions}

Figure 1. Change in current density, $i$, with anodizing time, $t_{a}$, in $0.3 \mathrm{M}$ acetylenedicarboxylic acid solutions over $180 \mathrm{~min}$ at a) 333, b) 313, c) 293, and d) 273 $\mathrm{K}$ and constant cell voltages in the range of $\mathrm{V}=87.5-97.5 \mathrm{~V}$. e) Surface appearances of specimen anodized at $293 \mathrm{~K}$ and $90.0-92.5 \mathrm{~V}$.

Figure 2. SEM images of the surface of the specimens a) before and b) after anodizing at $293 \mathrm{~K}$ and $90.0 \mathrm{~V}$ for $180 \mathrm{~min}$. c) High-magnification and d) cross-sectional SEM images of the anodized specimen shown in b). e) Surface images of the anodized specimens after selective oxide removal by $\mathrm{CrO}_{3} / \mathrm{H}_{3} \mathrm{PO}_{4}$ solution.

Figure 3. High-magnification SEM images of the cross-section of the anodic porous alumina formed by anodizing at $333 \mathrm{~K}$ and $95.0 \mathrm{~V}$ for $180 \mathrm{~min}$.

Table 1. Summary of the organic acids used for anodic porous alumina fabrication and corresponding anodizing voltages typically used. 
Table 1

\begin{tabular}{lll}
\hline Electrolyte & \multicolumn{1}{c}{ Chemical formula } & Typical anodizing voltage \\
\hline Oxalic & HOOC-COOH & $40 \mathrm{~V}$ for self-ordering \\
Malonic & $\mathrm{HOOC}-\mathrm{CH}_{2}-\mathrm{COOH}$ & $120 \mathrm{~V}$ for self-ordering \\
Tartaric & $\mathrm{HOOC}-(\mathrm{CHOH})_{2}-\mathrm{COOH}$ & $195 \mathrm{~V}$ for self-ordering \\
Malic & $\mathrm{HOOC}-\mathrm{CH}(\mathrm{OH})-\mathrm{CH}_{2}-\mathrm{COOH}$ & $200-250 \mathrm{~V} \mathrm{~V}^{23}$ \\
\hline Citric & $\mathrm{HOCO}^{14} \mathrm{CH}_{2}-\mathrm{C}(\mathrm{OH})(\mathrm{COOH})-\mathrm{CH}_{2}-\mathrm{COOH} \quad 260-450 \mathrm{~V}^{22}$ \\
Glycolic & $\mathrm{CH}_{2} \mathrm{OH}-\mathrm{COOH}$ & $150 \mathrm{~V}^{11}$ \\
\hline Acetylenedicarboxylic $\quad \mathrm{HOOC}-\mathrm{C} \equiv \mathrm{C}-\mathrm{COOH}$ & $87.5-95.0 \mathrm{~V}$ \\
\hline
\end{tabular}



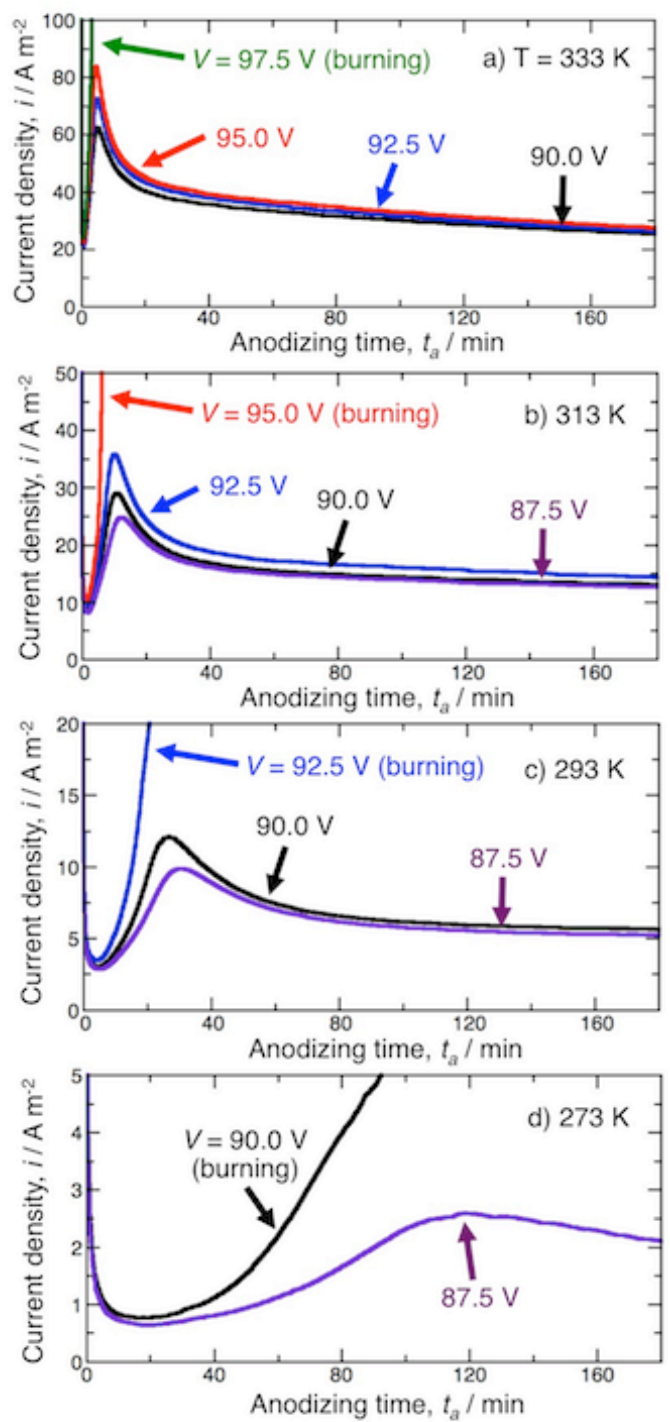

e) Surface appearances ( $T=293 \mathrm{~K}$ )

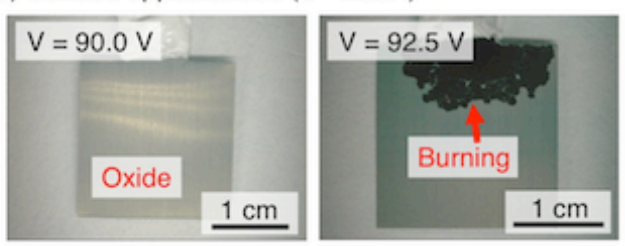

Fig. 1 

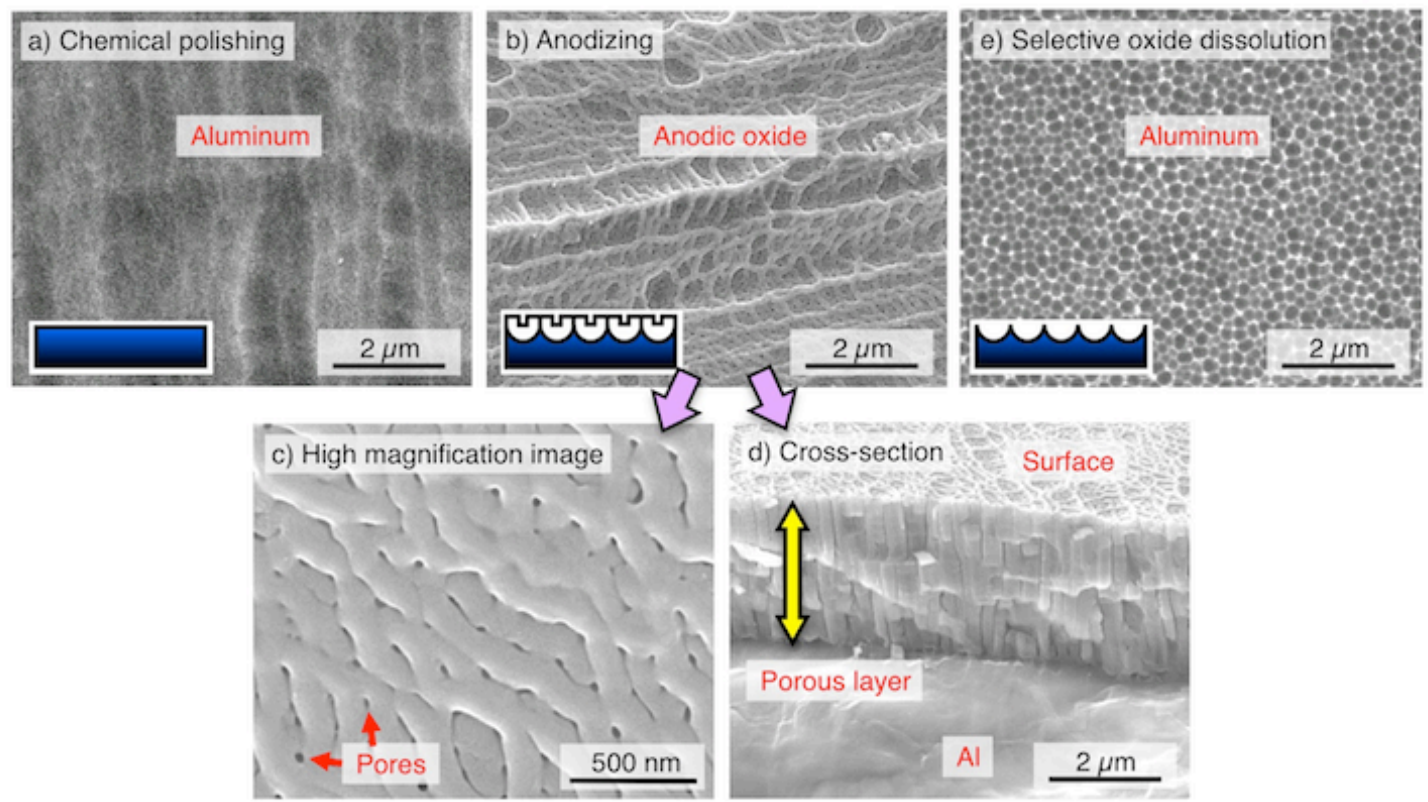

Fig. 2 


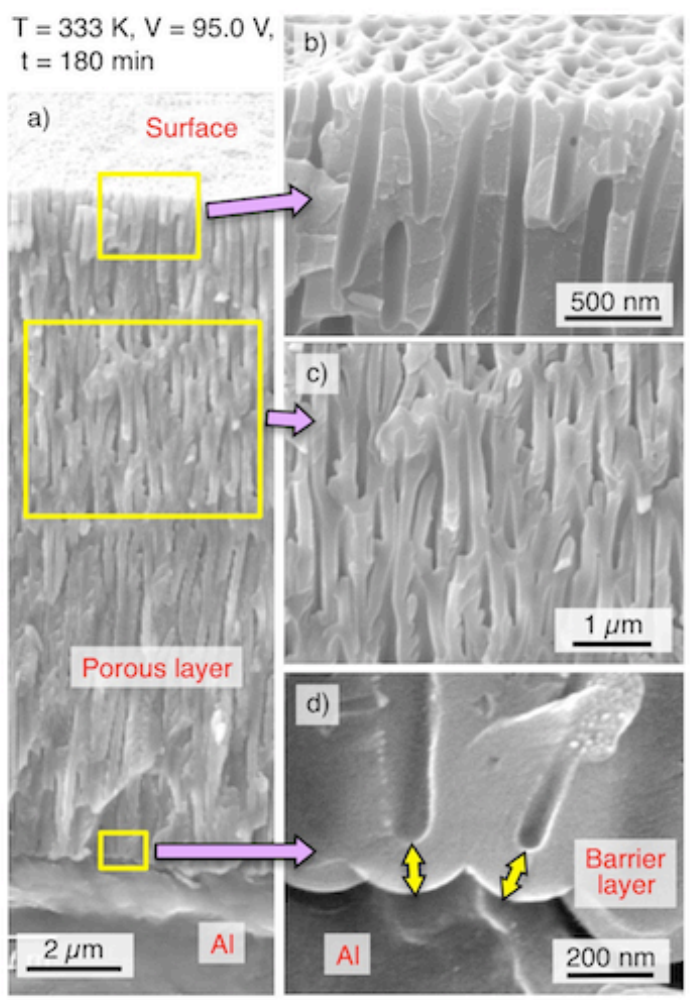

Fig. 3 